\title{
The Effects of Anesthetics on Recurrence and Metastasis of Cancer, and Clinical Implications
}

\author{
Wenjing Yang ${ }^{\mathrm{a}, \mathrm{b}}$, Jun Cai ${ }^{\mathrm{b}}$, Catherine Zabkiewicz ${ }^{\mathrm{b}}$, Huiming Zhang ${ }^{\mathrm{c}}$, \\ Fiona Ruge ${ }^{b}$, Wen G. Jiang ${ }^{\mathrm{b}, \mathrm{d}}$
}

\begin{abstract}
Surgical resection of the primary tumor may enhance the metastasis and recurrence of cancer. The reaction of patients to surgery includes changes of the immune system, the inflammatory system and the neuroendocrine system. In the perioperative period, anesthetics are used both for anesthesia and analgesia. There are several studies showing that the progression of cancer can be influenced by many kinds of anesthetics, although most of these studies are preclinical and thus have not yet influenced clinical recommendations. This review summarizes recent studies regarding the effects of anesthetics on metastasis and recurrence of cancer.
\end{abstract}

Keywords: Anaesthetic; Cancer; Metastasis; Recurrence

\section{Introduction}

For many cancers, surgical resection of the primary tumor is the mainstay of treatment; however, there is increasing evidence that this may actually promote the recurrence and metastasis of cancer. Whether this occurs depends largely on the tumor's ability to spread combined with the host immunity and inflammatory response [1]. There are many factors that impact on this perioperatively, such as surgical stress, blood transfusions, hypothermia, hyperglycemia, and postoperative pain. The immune system is suppressed by surgery, which promotes inflammation. Additionally, the endocrine system diminishes host tumor response. All these periopera-

Manuscript accepted for publication May 19, 2017

aDepartment of Anesthesiology, Beijing Tong Ren Hospital, Capital Medical University, Dong-Cheng, Beijing 100065, China

${ }^{b}$ Cardiff China Medical Research Collaborative, Division of Cancer and Genetics, Cardiff University School of Medicine, Heath Park, Cardiff CF14 4XN, UK

${ }^{\mathrm{c} D e p a r t m e n t ~ o f ~ G e n e r a l ~ S u r g e r y, ~ B e i j i n g ~ F r i e n d s h i p ~ H o s p i t a l, ~ C a p i t a l ~ M e d i c a l ~}$ University, Beijing, China

${ }^{\mathrm{d} C}$ Corresponding Author: Wenguo Jiang, Cardiff China Medical Research Collaborative, Division of Cancer and Genetics, Cardiff University School of Medicine, Heath Park, Cardiff CF14 4XN, UK. Email: JiangW@cardiff.ac.uk

doi: https://doi.org/10.14740/wjon1031e tive changes offer a favorable microenvironment, promoting residual and circulating cancer cells to proliferate and metastasize after operation [2]. Undergoing surgery thus creates the "perfect storm" [3], throughout which the judicious and careful selection of anesthetic and analgesia is vital, not only for safety purpose during the "storm", but also for optimal postoperative outcomes.

This has then raised the question of what impact the anesthesia itself has on this perioperative tumor promoting environment. Studies focus on four main fields: the effect on immune system, the effect on inflammatory system, the effect on the microenvironment and the direct effect on cancer cells. This review collates the evidence regarding anesthetic effects on metastasis and recurrence of cancer (Table 1) [417].

\section{The Effect of Surgery on the Progression of Cancer}

Surgery presents opportunities not only for eradicating tumors, but also for proliferation and invasion of residual cancer cells. Surgery increases the shedding of malignant cells into the blood and lymphatic circulations, inhibits their apoptosis and potentiates their invasion capacity [18]. Surgery also increases the factors related to tumor vascularity and levels of growth factors, endorsing local and distant recurrence. The immune system, the inflammatory system and the neuroendocrine system react to surgery with notable changes which have been proven to promote progression of cancer [19]. Psychological distress (anxiety, stress and depression) initiated by surgery, releases stress hormones and down-regulates cellular immune indices [20].

A successful metastasis of cancer cells is determined by their microenvironment. For example, without periostin which is released locally by fibroblasts within the tumor microenvironment, metastasizing breast cancer stem cells are unable to deposit in lung models [21]. In colorectal cancer, hepatocyte growth factor (HGF) secreted by myofibroblasts induces epithelial-mesenchymal transition (EMT) which is known to play a pivotal role in mediating invasion and metastasis [22]. The inflammatory mediators induced by pro-inflammatory cytokines (TNF- $\alpha$, IL-1 $\beta$ and IL-6), instigate and facilitate cross talk at the cancer cell-stromal interface. This promotes metastasis of tumor cells through initiation of metastatic coloniza- 

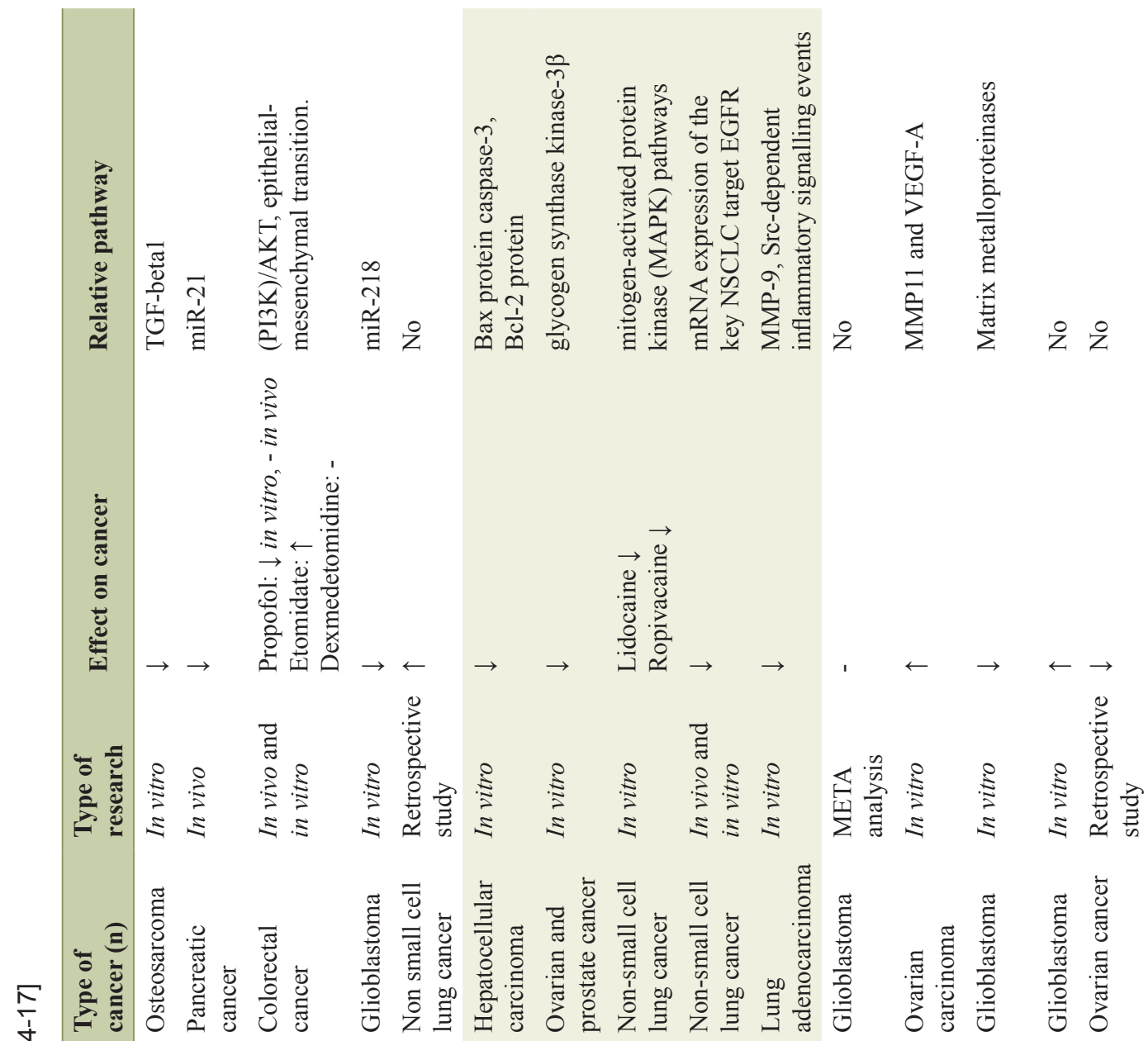

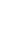

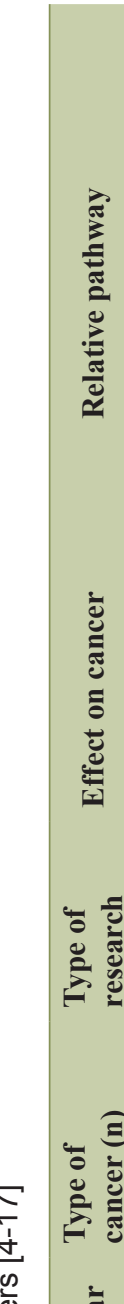

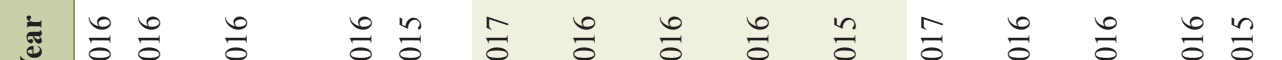

8

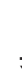

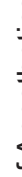

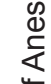

, 
tion, acting somewhat as a "fertilizer" to aid successful tumor growth [22].

Specific factors initiated by surgical trauma can influence the progression of cancer, including catecholamines, prostaglandins, glucocorticoids, various cytokines, pro-angiogenic factors, opioids, etc. [18]. Growth factors such as vascular endothelial growth factor (VEGF) and EGF, elevated by surgery, are demonstrated to potentiate the metastatic ability of cancer stem cells [23]. Many studies have particularly reported on the enhancement of catecholamines and prostaglandins on cancer development, both by immunosuppression and by direct facilitation of malignant tissue progression and the interventions to decrease the levels of these factors for a better prognosis have been taken on in clinical studies, as will be discussed in the following sections.

\section{The Effect of Volatile Agents on Cancer}

The anesthetic mechanism of volatile agents is complicated, targeting a number of sites including GABA receptors and NMDA receptors [3]. Studies in vitro and in vivo have shown that there is an association between inhalational anesthesia and increased tumor spread $[4,24]$. In a recent retrospective study, it was found that cancer patients had a worse survival outcome if they received inhalational anesthesia [25]. Inhalational anesthesia inhibits the immune system by decreasing the function of natural killer cells, which play an important role in protecting against proliferation of cancer cells [26]. It was reported that isoflurane could promote the growth and migration of glioblastoma cells [5], up-regulate levels of hypoxia-inducible factor (HIF) $-1 \alpha$ and HIF-2 $\alpha$ and intensified expression of VEGF A [27]. HIF-1 $\alpha$ is overexpressed in a variety of carcinomas and their metastases, and is deemed to be a transcriptional regulator of VEGF expression, mediating angiogenic responses [28, 29].

On the contrary, sevoflurane was found to attenuate VEGF level via DNA methylation [30]. Sevoflurane had a dose-dependent inhibition of glioma cells, not only by increasing the expression of miRNA637 and decreasing the expression of Akt1 and phosphorylated Akt1 [31], but also by inhibiting MMP-2 activity [6]. Liang et al found the invasion of lung cancer cells induced by platelets could be suppressed by sevoflurane via decreasing platelet activity [32]. Combined with 6 MV photon, sevoflurane down-regulated cdc42 overexpression and decreased the migration speed of human adenocarcinoma cell line A549, potentially providing clinical benefit for the cancer therapy [33]. However, Sugimoto et al have a contrary conclusion that sevoflurane enhances colon cancer cell line proliferation via K (ATP) channels in cancer cells [34]. Elias et al studied 194 women with stage III epithelial ovarian cancer undergoing optimal primary cytoreduction. They concluded that compared with sevoflurane, the use of desflurane was associated with a lower overall rate of ovarian cancer recurrence, and desflurane was independently associated with an improved disease-free survival [7]. As we know, there are a number of factors that need to be taken into account when interpreting these retrospective studies and prospective randomized controlled trials should be taken to verify these conclusions.

\section{The Effect of Intravenous Agents on Cancers}

\section{Propofol}

As a short-acting intravenous anesthetic agent, propofol is widely used for sedation and hypnosis during and after operation. It exerts anesthesia by activating GABA A receptors directly, to slow the channel-closing time and by blocking sodium channels [35]. A retrospective analysis compared propofol with sevoflurane and found the 1-year survival after colon cancer operation in the propofol group was almost $10 \%$ higher [36]. Ji et al concluded that propofol-based total intravenous anesthesia (TIVA) for breast cancer surgery can reduce the risk of recurrence during the initial 5 years after modified radical mastectomy [37]. Propofol is supposed to protect the immune system from being inhibited perioperatively $[35,38,39]$ and have a lower inflammatory response than volatile agents [40-42]. An in vivo study assessed propofol's effect on pulmonary cancer metastasis [43]. After administration of propofol or saline intravenously, 40 rats were injected with pulmonary cancer cells. Three weeks later, it was found the doses of propofol were inversely correlated with the number of pulmonary metastasis. Similarly, propofol drastically inhibited hepatocellular tumor growth in rat models [44].

Some studies in vitro focus on the direct effects of propofol on cancer cells. It can be concluded that propofol can induce apoptosis and inhibit the growth of cancer cells by activating different signal pathways. Deng et al found propofol inhibits migration of colorectal cancer cell (CRC), both in vitro and in vivo by activating (PI3K)/AKT signaling and inducing EMT [8]. Through downregulation of TGF- $\beta 1$ expression, propofol effectively inhibits proliferation and invasion and induces apoptosis of osteosarcoma cells [9]. Liu et al concluded propofol inhibits invasion and induces apoptosis of pancreatic cancer (PANC-1) cells by regulating MicroRNA (miR) -21/Slug signals [10]. Only one study has found the opposing conclusion that propofol induces proliferation and invasion of gallbladder cancer cells [45].

\section{Etomidate}

Etomidate has minimal effects on hemodynamics, and is thus considered for use particularly in older or critically ill, hemodynamically unstable patients. With respect to its inhibition of adrenal cortex function, etomidate is not recommended for immunosuppressed or septic patients. Very few studies have investigated the effect of etomidate on cancer. In one study in vivo, etomidate was found to reduce the viability of macrophages significantly, in a dose-dependent manner [46]. In a clinical study, they found etomidate had less effect on immune function in patients with lung adenocarcinoma than propofol [47]. 


\section{Alpha2-adrenoceptor agonists}

Dexmedetomidine (DEX) is a highly selective $\alpha 2$-adrenergic receptor agonist, used increasingly in operations for sedative, anxiolytic, and analgesic purposes. It was found that $\alpha 2$-adrenoceptors are expressed in human breast cancer cell lines, and activation of these receptors was associated with an enhancement of cell proliferation [48]. An in vivo murine study confirmed this conclusion [49]. In mice treated with DEX, there was a significant increase in tumor growth and metastasis, which was associated with an alteration in mammary tumor collagen microstructure [50]. Xia et al found DEX could promote the growth of established breast tumors in vivo through the activation of $\alpha 2 \beta$-adrenoceptor/ERK signaling [51]. However, a different study found DEX had minimal effect on the migration of CRCs [8].

\section{Opioids}

Opioid drugs are widely used to manage pain during and after operation. A retrospective analysis suggested an association between increased doses of opioids during the initial 96 $\mathrm{h}$ postoperative period, with a higher recurrence rate of nonsmall-cell lung cancer within 5 years [52]. Intraoperative opioid use is associated with decreased overall survival of nonsmall cell lung cancer (NSCLC) patients [11]. Similarly Forget et al found that intraoperative sufentanil administration was related to an increased risk of cancer recurrence after radical prostatectomy [53]. However, in a clinical trial, there were no differences in immunosuppression and recurrence between the opioid group and the ropivacaine group [54]. The limitation in this study was the short follow-up period of 12 months, and the immune function was assessed only by NK cell cytotoxicity (NKCC) and interleukin (IL)-2, not including T-helper cells and cytotoxic $\mathrm{T}$ cells.

It has been proved that opioid receptors exist not only in neurons but also in immune cells (granulocytes, monocytes/ macrophages, lymphocytes, and natural killer cells) [55] and tumor cells originating from glioma and colon, breast, lung, pancreatic, thyroid, endocrine and endometrial cancers. The expression of $\mu$ opioid receptors (MOR) in human lung cancer is significantly increased compared with adjacent control tissue $(P=0.0242)$ and is nearly two-fold higher in those with metastatic lung cancer in comparison to non-metastatic disease [56].

By stimulating these receptors, opioids exert their effects on tumors in myriad ways [57], which has both direct effect on the proliferation and invasion of tumor cells [58] and indirect effects on the tumor including immunosuppression, pro-inflammation and pro-angiogenesis [59]. An in vitro study showed morphine, an MOR activator, decreased tumor multiplication, and intermittent injections inhibited the proliferation of adenocarcinoma cells [60]. Afsharimani et al found morphine exerts anti-tumor effects through modulation of paracrine communication between cancer cells and nonmalignant cells in the tumor microenvironment [61]. A recent study found morphine promotes renal cell carcinoma growth and progression via over-expression of surviving [12]. Tumor development is often accompanied and enhanced by an inflammatory response. It has been pointed out that different types of opioid receptors have conflicting effects on inflammation and activating MOR induces a pro-inflammatory response which could enhance tumor development [62].

In addition, continuous administration of high doses of morphine is more likely to inhibit tumor growth and metastasis in rodent models. In contrast, intermittent injection induces withdrawal-like conditions and activates the hypothalamicpituitary-adrenal (HPA) axis which is known to facilitate cancer progression and metastasis [63]. So not only is the type of opioid receptor potentially important, but the method of dosing may influence whether opiate analgesia has a pro- or antitumor effect.

\section{Ketamine}

In a model of breast cancer metastasis, rats were anesthetized for $1 \mathrm{~h}$ with ketamine, thiopental, halothane, or propofol, and then injected IV with MADB106 tumor cells [26]. The number and activity of circulating NK cells after anesthesia and lung tumor retention $24 \mathrm{~h}$ later was assessed. Lung metastases were counted 3 weeks later. The author found ketamine caused a significant decrease in NK cells, and increased lung tumor retention and lung metastases most potently. This effect was markedly reduced in rats pre-treated with the beta blocker nadolol, or with chronic small doses of an immunostimulator. The authors suggest NK activity was suppressed by ketamine and this promoted MADB106 metastasis. He et al found ketamine can up-regulate the level of anti-apoptosis protein Bcl-2 and promotes breast cancer cell invasion and proliferation [64].

In contrast, in a recent study, ketamine was seen to inhibit pancreatic cancer cell proliferation and apoptosis as an N-methyl-D-aspartate (NMDA) antagonist [65]. It can be seen that ketamine has a pro-tumor effect by inhibition of immune functions, whereas its direct effect on cancer cells is still debatable.

\section{Non-steroidal anti-inflammatory drugs (NSAIDs)}

Inflammation plays an important role in cancer. Long-term administration of NSAIDs has shown to decrease the incidence, recurrence and proliferation of various cancers, such as colon, breast, lung, and pancreatic cancer [66]. But only a few studies have focused on the effect of perioperative use of NSAIDs. A retrospective study indicated that perioperative administration of ketorolac for lung cancer patients was marginally associated with better overall survival $(P=0.05)$ [67]. Forget et al found NSAIDs used at the beginning of the surgery is independently associated with a lower metastases risk after lung cancer surgery and ketorolac use is independently associated with longer survival [68]. Ketorolac given before surgery was also found to have a lower cancer recurrence rate [69]. In an in vivo murine model of tumor metastasis, there was no difference between continuous or perioperative treatment with celecoxib, a selective cyclooxygenase 2 inhibitor, as both modes of admin- 
istration decreased lung metastases significantly [70].

\section{The Effects of Local Anesthetics on Cancers}

Local anesthetics exert their effect by blocking voltage-gated sodium channels (VGSC) on the nerve cell membrane, which are also found on tumor cell membrane and are thought to be correlated with the invasion and metastasis of tumor cells [71]. Recent studies have focused on the anti-tumor properties of local anesthetics. Wang et al investigated the influence of local anesthetics on NSCLC cells, and found lidocaine and ropivacaine can inhibit the growth, invasion and migration of cancer cells, as well as induce their apoptosis [13]. The authors suggest the local anesthetics activate the mitogen-activated protein kinase (MAPK) pathway, caspases Bcl-2 and the intrinsic mitochondrial apoptosis pathway. Similar results can be found in the study of lung adenocarcinoma cells from Piegeler et al [14] and the study of breast cancer from Lirk et al [72], although the supposed mechanisms in these studies were different. In a very recent study, researchers applied lidocaine to human hepatocellular carcinoma cells in vitro and also in a xenograft model, and certified the anti-tumor effect of lidocaine [15]. In addition, lidocaine is supposed to sensitize breast cancer cells to the cytotoxicity of cisplatin [73] and have an effect on reversing cancer multidrug resistance [74].

The anti-tumor properties of local anesthetics offer a potential opportunity for clinical application. Intravenous use of lidocaine has been shown to possess an anti-inflammatory property [75]. In a prospective study, patients undergoing radical hysterectomy were given continuous infusion of lidocaine or the same volume of normal saline as control during operation [16]. The author found lidocaine treatment attenuated the early apoptosis of lymphocytes and preserved the ratio of interferon gamma to IL-4, which means lidocaine exerts a protective effect on cell-mediated immunity and may be beneficial in inhibiting tumor recurrence.

\section{Conclusion}

Taken together, when compared with other types of anesthetics, inhalation agents do not appear to be superior to intravenous agents in cancer operations. Isoflurane can enhance proliferation and metastasis of cancer cells in vitro and rodent, while sevoflurane seems to possess an anti-tumor property in most studies. Most of current studies agree that propofol possesses an anti-tumor property including immune-modulation, anti-inflammation and inhibition of cancer cells proliferation and invasion. NSAIDs possess an anti-tumor quality which is confirmed by clinical studies. The perioperative (short term) use of NSAIDs seems to have a similar effect, which needs prospective clinical studies. Opioid seems to have paradoxical effects on tumors, due to combinations of intricate mechanisms, including inhibition of cancer cells proliferation, immunosuppression, pro-inflammation and alleviation of pain and stress. In addition, types of tumor, different doses and patterns of administration may result in inverse responses.
Amide-linked local anesthetics may have anti-tumor properties.

Thus, anesthetic selection may well influence the prognosis of cancer patients. However, studies in vitro and in animal models are not always truly reflective of the human clinical position. Until now, most of the clinical studies are retrospective, and some of them are contradictory. With no official consensus, the effect of anesthetics and analgesics on cancer requires further study, particularly with regards to prospective randomized controlled trials.

\section{Acknowledgments}

The authors wish to thank Cancer Research Wales, Cardiff China Medical Scholarship for supporting this work.

\section{Conflicts of Interest}

All authors declare that they have no conflicts of interest.

\section{References}

1. Vogelaar FJ, Lips DJ, van Dorsten FR, Lemmens VE, Bosscha K. Impact of anaesthetic technique on survival in colon cancer: a review of the literature. Gastroenterol Rep (Oxf). 2016;4(1):30-34.

2. Xu YJ, Li SY, Cheng Q, Chen WK, Wang SL, Ren Y, Miao $\mathrm{CH}$. Effects of anaesthesia on proliferation, invasion and apoptosis of LoVo colon cancer cells in vitro. Anaesthesia. 2016;71(2):147-154.

3. Evans DR, Fowler-Williams C, Ma D. Is Volatile Anesthesia During Cancer Surgery Likely to Increase the Metastatic Risk? Int Anesthesiol Clin. 2016;54(4):92-107.

4. Iwasaki M, Zhao H, Jaffer T, Unwith S, Benzonana L, Lian Q, Sakamoto A, et al. Volatile anaesthetics enhance the metastasis related cellular signalling including CXCR2 of ovarian cancer cells. Oncotarget. 2016;7(18):2604226056.

5. Zhu M, Li M, Zhou Y, Dangelmajer S, Kahlert UD, Xie $\mathrm{R}, \mathrm{Xi}$ Q, et al. Isoflurane enhances the malignant potential of glioblastoma stem cells by promoting their viability, mobility in vitro and migratory capacity in vivo. $\mathrm{Br} \mathrm{J}$ Anaesth. 2016;116(6):870-877.

6. Hurmath FK, Mittal M, Ramaswamy P, Umamaheswara Rao GS, Dalavaikodihalli Nanjaiah N. Sevoflurane and thiopental preconditioning attenuates the migration and activity of MMP-2 in U87MG glioma cells. Neurochem Int. 2016;94:32-38.

7. Elias KM, Kang S, Liu X, Horowitz NS, Berkowitz RS, Frendl G. Anesthetic selection and disease-free survival following optimal primary cytoreductive surgery for stage III epithelial ovarian cancer. Ann Surg Oncol. 2015;22(4):1341-1348.

8. Deng F, Ouyang M, Wang X, Yao X, Chen Y, Tao T, Sun $X$, et al. Differential role of intravenous anesthetics in 
colorectal cancer progression: implications for clinical application. Oncotarget. 2016;7(47):77087-77095.

9. Xu YB, Jiang W, Zhao FR, Li G, Du QH, Zhang MY, Guo XG. Propofol suppresses invasion and induces apoptosis of osteosarcoma cell in vitro via downregulation of TGF-beta1 expression. Eur Rev Med Pharmacol Sci. 2016;20(7):1430-1435.

10. Liu Z, Zhang J, Hong G, Quan J, Zhang L, Yu M. Propofol inhibits growth and invasion of pancreatic cancer cells through regulation of the miR-21/Slug signaling pathway. Am J Transl Res. 2016;8(10):4120-4133.

11. Cata JP, Keerty V, Keerty D, Feng L, Norman PH, Gottumukkala V, Mehran JR, et al. A retrospective analysis of the effect of intraoperative opioid dose on cancer recurrence after non-small cell lung cancer resection. Cancer Med. 2014;3(4):900-908.

12. Ma Y, Ren Z, Ma S, Yan W, He M, Wang D, Ding P. Morphine enhances renal cell carcinoma aggressiveness through promotes survivin level. Ren Fail. 2017;39(1):258-264.

13. Wang HW, Wang LY, Jiang L, Tian SM, Zhong TD, Fang XM. Amide-linked local anesthetics induce apoptosis in human non-small cell lung cancer. J Thorac Dis. 2016;8(10):2748-2757.

14. Piegeler T, Votta-Velis EG, Liu G, Place AT, Schwartz DE, Beck-Schimmer B, Minshall RD, et al. Antimetastatic potential of amide-linked local anesthetics: inhibition of lung adenocarcinoma cell migration and inflammatory Src signaling independent of sodium channel blockade. Anesthesiology. 2012;117(3):548-559.

15. Xing W, Chen DT, Pan JH, Chen YH, Yan Y, Li Q, Xue RF, et al. Lidocaine Induces Apoptosis and Suppresses Tumor Growth in Human Hepatocellular Carcinoma Cells In Vitro and in a Xenograft Model In Vivo. Anesthesiology. 2017;126(5):868-881.

16. Wang HL, Yan HD, Liu YY, Sun BZ, Huang R, Wang $\mathrm{XS}$, Lei WF. Intraoperative intravenous lidocaine exerts a protective effect on cell-mediated immunity in patients undergoing radical hysterectomy. Mol Med Rep. 2015;12(5):7039-7044.

17. Xuan W, Zhao H, Hankin J, Chen L, Yao S, Ma D. Local anesthetic bupivacaine induced ovarian and prostate cancer apoptotic cell death and underlying mechanisms in vitro. Sci Rep. 2016;6:26277.

18. Neeman E, Ben-Eliyahu S. Surgery and stress promote cancer metastasis: new outlooks on perioperative mediating mechanisms and immune involvement. Brain Behav Immun. 2013;30(Suppl):S32-40.

19. Gottschalk A, Sharma S, Ford J, Durieux ME, Tiouririne M. Review article: the role of the perioperative period in recurrence after cancer surgery. Anesth Analg. 2010;110(6):1636-1643.

20. Thornton LM, Andersen BL, Blakely WP. The pain, depression, and fatigue symptom cluster in advanced breast cancer: covariation with the hypothalamic-pituitary-adrenal axis and the sympathetic nervous system. Health Psychol. 2010;29(3):333-337.

21. Malanchi I, Santamaria-Martinez A, Susanto E, Peng H, Lehr HA, Delaloye JF, Huelsken J. Interactions between cancer stem cells and their niche govern metastatic colonization. Nature. 2011;481(7379):85-89.

22. O'Leary DP, O'Leary E, Foley N, Cotter TG, Wang JH, Redmond HP. Effects of surgery on the cancer stem cell niche. Eur J Surg Oncol. 2016;42(3):319-325.

23. Ceelen W, Pattyn P, Mareel M. Surgery, wound healing, and metastasis: recent insights and clinical implications. Crit Rev Oncol Hematol. 2014;89(1):16-26.

24. Hooijmans CR, Geessink FJ, Ritskes-Hoitinga M, Scheffer GJ. A Systematic Review of the Modifying Effect of Anaesthetic Drugs on Metastasis in Animal Models for Cancer. PLoS One. 2016;11(5):e0156152.

25. Wigmore TJ, Mohammed K, Jhanji S. Long-term Survival for Patients Undergoing Volatile versus IV Anesthesia for Cancer Surgery: A Retrospective Analysis. Anesthesiology. 2016;124(1):69-79.

26. Melamed R, Bar-Yosef S, Shakhar G, Shakhar K, BenEliyahu S. Suppression of natural killer cell activity and promotion of tumor metastasis by ketamine, thiopental, and halothane, but not by propofol: mediating mechanisms and prophylactic measures. Anesth Analg. 2003;97(5):1331-1339.

27. Benzonana LL, Perry NJ, Watts HR, Yang B, Perry IA, Coombes C, Takata $\mathrm{M}$, et al. Isoflurane, a commonly used volatile anesthetic, enhances renal cancer growth and malignant potential via the hypoxia-inducible factor cellular signaling pathway in vitro. Anesthesiology. 2013;119(3):593-605.

28. Bentov I, Reed MJ. Anesthesia, microcirculation, and wound repair in aging. Anesthesiology. 2014;120(3):760772.

29. Zhang Q, Chen Y, Zhang B, Shi B, Weng W, Chen Z, Guo $\mathrm{N}$, et al. Hypoxia-inducible factor-1 alpha polymorphisms and risk of cancer metastasis: a meta-analysis. PLoS One. 2013;8(8):e70961.

30. Lu Y, Wang J, Yan J, Yang Y, Sun Y, Huang Y, Hu R, et al. Sevoflurane attenuate hypoxia-induced VEGF level in tongue squamous cell carcinoma cell by upregulating the DNA methylation states of the promoter region. Biomed Pharmacother. 2015;71:139-145.

31. Yi W, Li D, Guo Y, Zhang Y, Huang B, Li X. Sevoflurane inhibits the migration and invasion of glioma cells by upregulating microRNA-637. Int J Mol Med. 2016;38(6):1857-1863.

32. Liang H, Yang CX, Zhang B, Zhao ZL, Zhong JY, Wen XJ. Sevoflurane attenuates platelets activation of patients undergoing lung cancer surgery and suppresses plateletsinduced invasion of lung cancer cells. J Clin Anesth. 2016;35:304-312.

33. Feng Y, Feng J, Huang Z. SU-F-T-675: Down-Regulating the Expression of Cdc42 and Inhibition of Migration of A549 with Combined Treatment of Ionizing Radiation and Sevoflurane. Med Phys. 2016;43:3619.

34. Sugimoto H, Kawaraguchi Y, Nomura Y, Nishiwada T, Uemura K, Furuya H, Kawaguchi M. [Exposure to $1 \%$ Sevoflurane for 6 Hours Enhances Proliferation of Human Colon Cancer Cells]. Masui. 2015;64(4):357-361.

35. Fan W, Zhu X, Wu L, Wu Z, Li D, Huang F, He H. Propofol: an anesthetic possessing neuroprotective effects. Eur 
Rev Med Pharmacol Sci. 2015;19(8):1520-1529.

36. Enlund M, Berglund A, Andreasson K, Cicek C, Enlund A, Bergkvist L. The choice of anaesthetic - sevoflurane or propofol - and outcome from cancer surgery: a retrospective analysis. Ups J Med Sci. 2014;119(3):251-261.

37. Lee JH, Kang SH, Kim Y, Kim HA, Kim BS. Effects of propofol-based total intravenous anesthesia on recurrence and overall survival in patients after modified radical mastectomy: a retrospective study. Korean J Anesthesiol. 2016;69(2):126-132.

38. Chen Y, Liang M, Zhu Y, Zhou D. [The effect of propofol and sevoflurane on the perioperative immunity in patients under laparoscopic radical resection of colorectal cancer]. Zhonghua Yi Xue Za Zhi. 2015;95(42):3440-3444.

39. Jaura AI, Flood G, Gallagher HC, Buggy DJ. Differential effects of serum from patients administered distinct anaesthetic techniques on apoptosis in breast cancer cells in vitro: a pilot study. Br J Anaesth. 2014;113(Suppl 1):i6367.

40. Baki ED, Aldemir M, Kokulu S, Koca HB, Ela Y, Sivaci RG, Ozturk NK, et al. Comparison of the effects of desflurane and propofol anesthesia on the inflammatory response and s100beta protein during coronary artery bypass grafting. Inflammation. 2013;36(6):1327-1333.

41. Liu S, Gu X, Zhu L, Wu G, Zhou H, Song Y, Wu C. Effects of propofol and sevoflurane on perioperative immune response in patients undergoing laparoscopic radical hysterectomy for cervical cancer. Medicine (Baltimore). 2016;95(49):e5479.

42. Liu TC. Influence of propofol, isoflurane and enflurance on levels of serum interleukin- 8 and interleukin-10 in cancer patients. Asian Pac J Cancer Prev. 2014;15(16):67036707.

43. Zhang Y, Lin C, Wang W, Chen Y. [Effects of propofol on pulmonary metastasis of intravenous injected tumor cells and expressions of MTA1 and Wnt1 in rats]. Nan Fang Yi Ke Da Xue Xue Bao. 2014;34(7):1011-1015.

44. Zhang J, Shan WF, Jin TT, Wu GQ, Xiong XX, Jin HY, Zhu SM. Propofol exerts anti-hepatocellular carcinoma by microvesicle-mediated transfer of miR-142-3p from macrophage to cancer cells. J Transl Med. 2014;12:279.

45. Zhang L, Wang N, Zhou S, Ye W, Jing G, Zhang M. Propofol induces proliferation and invasion of gallbladder cancer cells through activation of Nrf2. Journal of Experimental \& Clinical Cancer Research. 2012;31:66.

46. Liu M, Zhang Y, Xiong JY, Wang Y, Lv S. Etomidate Mitigates Lipopolysaccharide-Induced CD14 and TREM-1 Expression, NF-kappaB Activation, and Pro-inflammatory Cytokine Production in Rat Macrophages. Inflammation. 2016;39(1):327-335.

47. Liu J, Dong W, Wang T, Liu L, Zhan L, Shi Y, Han J. Effects of etomidate and propofol on immune function in patients with lung adenocarcinoma. Am J Transl Res. 2016;8(12):5748-5755.

48. Vazquez SM, Mladovan AG, Perez C, Bruzzone A, Baldi A, Luthy IA. Human breast cell lines exhibit functional alpha2-adrenoceptors. Cancer Chemother Pharmacol. 2006;58(1):50-61.

49. Bruzzone A, Pinero CP, Castillo LF, Sarappa MG, Rojas
P, Lanari C, Luthy IA. Alpha2-adrenoceptor action on cell proliferation and mammary tumour growth in mice. $\mathrm{Br} \mathrm{J}$ Pharmacol. 2008;155(4):494-504.

50. Szpunar MJ, Burke KA, Dawes RP, Brown EB, Madden KS. The antidepressant desipramine and alpha2-adrenergic receptor activation promote breast tumor progression in association with altered collagen structure. Cancer Prev Res (Phila). 2013;6(12):1262-1272.

51. Xia M, Ji NN, Duan ML, Tong JH, Xu JG, Zhang YM, Wang SH. Dexmedetomidine regulate the malignancy of breast cancer cells by activating alpha2-adrenoceptor/ ERK signaling pathway. Eur Rev Med Pharmacol Sci. 2016;20(16):3500-3506.

52. Maher DP, Wong W, White PF, McKenna R, Jr., Rosner $\mathrm{H}$, Shamloo B, Louy C, et al. Association of increased postoperative opioid administration with non-small-cell lung cancer recurrence: a retrospective analysis. $\mathrm{Br} \mathrm{J}$ Anaesth. 2014;113(Suppl 1):i88-94.

53. Forget P, Tombal B, Scholtes JL, Nzimbala J, Meulders $\mathrm{C}$, Legrand C, Van Cangh P, et al. Do intraoperative analgesics influence oncological outcomes after radical prostatectomy for prostate cancer? Eur J Anaesthesiol. 2011;28(12):830-835.

54. Kim SY, Kim NK, Baik SH, Min BS, Hur H, Lee J, Noh HY, et al. Effects of Postoperative Pain Management on Immune Function After Laparoscopic Resection of Colorectal Cancer: A Randomized Study. Medicine (Baltimore). 2016;95(19):e3602.

55. Iwaszkiewicz KS, Schneider JJ, Hua S. Targeting peripheral opioid receptors to promote analgesic and antiinflammatory actions. Front Pharmacol. 2013;4:132.

56. Singleton PA, Mirzapoiazova T, Hasina R, Salgia R, Moss $\mathrm{J}$. Increased mu-opioid receptor expression in metastatic lung cancer. Br J Anaesth. 2014;113(Suppl 1):i103-108.

57. Bajwa SJ, Anand S, Kaur G. Anesthesia and cancer recurrences: The current knowledge and evidence. J Cancer Res Ther. 2015;11(3):528-534.

58. Afsharimani B, Cabot P, Parat MO. Morphine and tumor growth and metastasis. Cancer Metastasis Rev. 2011;30(2):225-238.

59. Grandhi RK, Lee S, Abd-Elsayed A. Does Opioid Use Cause Angiogenesis and Metastasis? Pain Med. 2017;18(1):140-151.

60. Tegeder I, Grosch S, Schmidtko A, Haussler A, Schmidt $\mathrm{H}$, Niederberger E, Scholich K, et al. G protein-independent G1 cell cycle block and apoptosis with morphine in adenocarcinoma cells: involvement of p53 phosphorylation. Cancer Res. 2003;63(8):1846-1852.

61. Afsharimani B, Baran J, Watanabe S, Lindner D, Cabot PJ, Parat MO. Morphine and breast tumor metastasis: the role of matrix-degrading enzymes. Clin Exp Metastasis. 2014;31(2):149-158.

62. Finley MJ, Happel CM, Kaminsky DE, Rogers TJ. Opioid and nociceptin receptors regulate cytokine and cytokine receptor expression. Cell Immunol. 2008;252(1-2):146154.

63. Afsharimani B, Doornebal CW, Cabot PJ, Hollmann MW, Parat MO. Comparison and analysis of the animal models used to study the effect of morphine on tumour growth 
and metastasis. Br J Pharmacol. 2015;172(2):251-259.

64. He H, Chen J, Xie WP, Cao S, Hu HY, Yang LQ, Gong B. Ketamine used as an acesodyne in human breast cancer therapy causes an undesirable side effect, upregulating anti-apoptosis protein Bcl-2 expression. Genet Mol Res. 2013;12(2):1907-1915.

65. Malsy M, Gebhardt K, Gruber M, Wiese C, Graf B, Bundscherer A. Effects of ketamine, s-ketamine, and MK 801 on proliferation, apoptosis, and necrosis in pancreatic cancer cells. BMC Anesthesiol. 2015;15:111.

66. Suthar SK, Sharma M. Recent Developments in Chimeric NSAIDs as Anticancer Agents: Teaching an Old Dog a New Trick. Mini Rev Med Chem. 2016;16(15):12011218.

67. Choi JE, Villarreal J, Lasala J, Gottumukkala V, Mehran RJ, Rice D, Yu J, et al. Perioperative neutrophil:lymphocyte ratio and postoperative NSAID use as predictors of survival after lung cancer surgery: a retrospective study. Cancer Med. 2015;4(6):825-833.

68. Forget P, Machiels JP, Coulie PG, Berliere M, Poncelet AJ, Tombal B, Stainier A, et al. Neutrophil:lymphocyte ratio and intraoperative use of ketorolac or diclofenac are prognostic factors in different cohorts of patients undergoing breast, lung, and kidney cancer surgery. Ann Surg Oncol. 2013;20(Suppl 3):S650-660.

69. Forget P, Vandenhende J, Berliere M, Machiels JP, Nussbaum B, Legrand C, De Kock M. Do intraopera- tive analgesics influence breast cancer recurrence after mastectomy? A retrospective analysis. Anesth Analg. 2010;110(6):1630-1635.

70. Backhus LM, Sievers E, Lin GY, Castanos R, Bart RD, Starnes VA, Bremner RM. Perioperative cyclooxygenase 2 inhibition to reduce tumor cell adhesion and metastatic potential of circulating tumor cells in non-small cell lung cancer. J Thorac Cardiovasc Surg. 2006;132(2):297-303.

71. Koltai T. Voltage-gated sodium channel as a target for metastatic risk reduction with re-purposed drugs. F1000Res. 2015;4:297.

72. Lirk P, Berger R, Hollmann MW, Fiegl H. Lidocaine time- and dose-dependently demethylates deoxyribonucleic acid in breast cancer cell lines in vitro. Br J Anaesth. 2012;109(2):200-207.

73. Li K, Yang J, Han X. Lidocaine sensitizes the cytotoxicity of cisplatin in breast cancer cells via up-regulation of RARbeta 2 and RASSF1A demethylation. Int J Mol Sci. 2014; 15(12):23519-23536.

74. Hu Y, Qin X, Cao H, Yu S, Feng J. Reversal effects of local anesthetics on P-glycoprotein-mediated cancer multidrug resistance. Anticancer Drugs. 2017;28(3):243-249.

75. Herroeder S, Pecher S, Schonherr ME, Kaulitz G, Hahnenkamp K, Friess H, Bottiger BW, et al. Systemic lidocaine shortens length of hospital stay after colorectal surgery: a double-blinded, randomized, placebo-controlled trial. Ann Surg. 2007;246(2):192-200. 